\title{
Playas críticas por erosión costera en el caribe sur de Costa Rica, durante el periodo 2005-2016
}

\section{Critical beaches due to coastal erosion in the Caribbean south of Costa Rica during the period 2005-2016}

\author{
Gustavo Barrantes-Castillo ${ }^{1}$ \\ Isabel Arozarena-Llopis ${ }^{2}$ \\ Luis Fernando Sandoval-Murillo ${ }^{3}$ \\ José Francisco Valverde-Calderón ${ }^{4}$ \\ Universidad Nacional, Costa Rica
}

\begin{abstract}
Resumen
Desde el 2010 en la prensa local se ha venido reportando un proceso acelerado de erosión en playas arenosas del litoral caribeño costarricense, que incluso ha sido documentado al interior de las áreas protegidas. Para cuantificar este proceso e identificar los puntos calientes por erosión costera en el Caribe Sur, se planteó una metodología que consiste en levantar la línea de costa a partir de fotografías áreas e imágenes satelitales de alta resolución espacial, con el fin de determinar la tasa de retroceso de la costa. Las fotos e imágenes utilizadas cubren un periodo entre 2005 y 2016. De esta forma fue posible identificar once puntos calientes de erosión, así como la estimación de sus tasas areales de retroceso para dos periodos (2005-2010 y 2010-2016). En este sentido, las localidades que han experimentado la mayor erosión en sus playas arenosas son el Parque Nacional Cahuita, Westfalia y playa Bananito.
\end{abstract}

Palabras clave: erosión costera, Caribe costarricense, dinámica costera, provincia de Limón, erosión de playas.

1 Doctor, Escuela de Ciencias Geográficas, Universidad Nacional, Costa Rica. Correo electrónico: gbarrantes@ una.cr

2 Doctora, Departamento de Física, Universidad Nacional, Costa Rica. Correo electrónico: iarozarena@ gmail.com

3 Máster, Escuela de Ciencias Geográficas, Universidad Nacional, Costa Rica. Correo electrónico: luis.sandoval.murillo@una.cr

4 Ingeniero, Escuela de Topografía Catastro y Catastro, Universidad Nacional, Costa Rica. Correo electrónico: jose.valverde.calderon@una.cr 


\begin{abstract}
Since 2010, the local press has been reporting an accelerated process of erosion on the sandy beaches of the Costa Rican Caribbean coast, it has even been documented within protected areas. To quantify this process and identify coastal erosion hotspots in the Caribbean south, a methodology was proposed for detecting and delineating the shoreline using aerial photographs and high-resolution satellite imagery to determine the rate of coastline retreat, the employed photographs and images cover the period between 2005 and 2016. By such means it was possible to identify eleven erosion hotspots, as well as estimation of their retreat rates for the periods 2005-2010 and 20102016. The localities that have experienced the greatest erosion of their sandy beaches are Cahuita National Park, Westfalia and Bananito Beach.
\end{abstract}

Keywords: Coastal erosion; Costa Rican Caribbean; Coastal dynamics; Limón province; Erosion of beaches.

\title{
Introducción
}

Las playas de arena son formaciones muy comunes en las costas tropicales (Gerrard, 2007). Se trata de una forma costera en la cual se da una transición entre los ambientes marino y terrestre (Dingler, 2005). La erosión de playas arenosas puede ser analizada como un balance negativo entre la entrada y salida de sedimentos de la playa, que resulta en un cambio morfológico que comúnmente es percibido por los ocupantes de estos espacios como un retroceso en la línea de costa (Masselink, 2012). Este balance negativo puede ser provocado por una amplia variedad de causas entre las que se encuentran los cambios en el uso del suelo de las cuencas hidrográficas, la disminución del aporte de sedimentos de los ríos como resultado de la construcción de represas, la edificación de infraestructura costera, cambios en el viento, oleaje, el patrón de las tormentas o en el nivel medio del mar.

De acuerdo con Silva, et al. (2014), en América Latina la erosión costera no es un problema generalizado, sin embargo, se encuentra extendida y resulta ser un problema grave en determinados sitios. En el caso de Costa Rica, en los últimos 15 años algunos investigadores han advertido sobre los efectos de los cambios en la línea de la costa Pacífica (Lizano et al., 2002; Denyer et al., 2004 y Ortiz, 2012). Más recientemente, Lizano (2013) reporta procesos de erosión en playas que se encuentran en áreas protegidas y sitios turísticos de la costa Caribe costarricense, hechos que son rápidamente asociados con el cambio climático (Quesada \& Molina, 2016) sin que existan estudios que permitan cuantificar el proceso, establecer tendencias o explorar otras posibles causas. 
En este sentido, el estudio realizado en el marco del proyecto Biodiversidad Marino Costera en Costa Rica, Desarrollo de Capacidades y Adaptación al Cambio Climático (BIOMARCC-SINAC-GIZ, 2013), elaboró un mapa donde presenta las áreas de costa potencialmente afectadas como resultado del aumento en el nivel del mar, en el cual se brindan cinco categorías de exposición en función de sus elevaciones en metros sobre el nivel del mar (msnm), a saber: muy alta $0-1 \mathrm{msnm}$; alta 1-2 msnm; media 2-4 msnm; baja 4-8 msnm; y muy baja 8-16 msnm. Con base en esta clasificación, la zona costera Caribe experimentaría un amplio impacto a causa del cambio del nivel del mar vinculado al cambio climático. De acuerdo con este mismo estudio, se indica que el mar Caribe tiene una tendencia al aumento del nivel del mar (1-2 mm/año), no obstante, señalan que este fenómeno puede ser atribuido a la variabilidad multidecadal del ENSO, o a un cambio en la Circulación de la Corriente del Caribe (CC) y el Giro Panamá Colombia (GPC).

Cabe resaltar que se ha reportado un proceso de erosión acelerada en varios sectores del Caribe Sur en playas como Cieneguita (Bosque, 2016; Mora, 2015; Barrantes, et al., 2017), el Parque Nacional Cahuita (Soto, 2014) y el refugio de vida silvestre Gandoca-Manzanillo (Quesada \& Molina, 2016). Debido a lo anterior, se ha desarrollado esta investigación que busca identificar y cuantificar las áreas de mayor erosión en las playas, denominadas puntos calientes o hot spots en inglés (Finkl, 1993) que se localizan entre Puerto Limón y la desembocadura del río Sixaola, frontera con Panamá. Su identificación y cuantificación precisa resulta central en la planificación de las zonas costeras, en particular en sitios de donde se ubican infraestructuras (Anthony, 2005).

\section{Cálculo de la erosión costera}

La erosión costera puede ser estudiada en marcos espacio temporales distintos, que se relacionan con los procesos que provocan en los cambios, así como con las técnicas para su estudio (Tabla 1). 
Tabla 1. Escalas de análisis de la erosión costera

\begin{tabular}{|c|c|c|c|}
\hline Periodo & $\begin{array}{c}\text { Escala espacial y } \\
\text { temporal }\end{array}$ & $\begin{array}{c}\text { Procesos que influyen } \\
\text { en los cambios }\end{array}$ & Método de estudio \\
\hline Muy corto plazo & $\begin{array}{c}\text { De mm a m } \\
\text { De segundos a horas }\end{array}$ & $\begin{array}{c}\text { Oleajes, corrientes y } \\
\text { vientos }\end{array}$ & $\begin{array}{c}\text { Introducción de arena } \\
\text { marcada con color o } \\
\text { fluorescente. } \\
\text { Varillas segmentadas } \\
\text { de aluminio } \\
\end{array}$ \\
\hline Corto plazo & $\begin{array}{c}\text { De } \mathrm{m} \text { a km } \\
\text { De horas a años }\end{array}$ & $\begin{array}{c}\text { Oleajes, vientos, } \\
\text { mareas, marejadas, } \\
\text { cambios estacionales y } \\
\text { tormentas }\end{array}$ & $\begin{array}{c}\text { Cambios en el perfil de } \\
\text { playa } \\
\text { GPS diferencial }\end{array}$ \\
\hline Mediano Plazo & $\begin{array}{c}\text { kilómetros } \\
\text { De años a décadas }\end{array}$ & $\begin{array}{c}\text { Cambios en el régimen } \\
\text { de oleaje, tormentas } \\
\text { severas, cambio en el } \\
\text { aporte de sedimentos de } \\
\text { los ríos, obras sobre el } \\
\text { litoral } \\
\end{array}$ & $\begin{array}{l}\text { Fotografías aéreas } \\
\text { Imágenes satelitales } \\
\text { y ortofotografías } \\
\text { analizadas en SIG }\end{array}$ \\
\hline Largo Plazo & $\begin{array}{l}\text { Decenas de } \mathrm{km} \\
\text { De décadas a centurias }\end{array}$ & $\begin{array}{c}\text { Cambios en el } \\
\text { transporte de los } \\
\text { sedimentos y cambios } \\
\text { en el nivel del mar }\end{array}$ & $\begin{array}{l}\text { Técnicas de estudios } \\
\text { cuaternarios (foto- } \\
\text { geomorfología, } \\
\text { arqueología, } \\
\text { sedimentología, entre } \\
\text { otros) }\end{array}$ \\
\hline Muy Largo Plazo & $\begin{array}{c}\text { Cientos de Km } \\
\text { De centurias a milenios }\end{array}$ & $\begin{array}{c}\text { Cambios en el nivel del } \\
\text { mar, variaciones en el } \\
\text { aporte de sedimentos } \\
\text { y cambios de oleaje } \\
\text { regional. }\end{array}$ & $\begin{array}{l}\text { Técnicas de estudios } \\
\text { cuaternarios (foto- } \\
\text { geomorfología, } \\
\text { arqueología, } \\
\text { sedimentología, etc.) }\end{array}$ \\
\hline
\end{tabular}

Fuente: elaboración propia a partir de (Taveira-Pinto et al., 2011) y Gracia et al., (2005).

Por el tipo de fuentes utilizadas y los métodos de análisis esta investigación se embarca en el mediano plazo. Así mismo, las tasas de la erosión pueden ser calculadas de tres formas distintas (Ojeda, 2000; Prieto, 2017):

- Cálculo de distancias (m/año): se determina a partir del registro de la distancia de retroceso de dos o más líneas de costa. También se puede obtener por medio de perfiles de playa o distancias medidas en campo desde puntos fijos de referencia.

- Cálculo de superficies (m2/año): se basa en la elaboración de polígonos entre dos líneas de costa levantadas en diferentes fechas. 
- Cálculo de volumen (m3/año): para su obtención se requiere de levantamientos topográficos con altimetría de alta precisión de la playa en estudio.

De estos procedimientos, el cálculo de volúmenes aporta más información por incorporar tres dimensiones (3D) en su análisis, pero resultan muy costosos por los equipos involucrados (GPS deferido o sensores aerotransportados LiDAR). El cálculo de superficie que ofrece un análisis en dos dimensiones (2D), para su implementación requiere definir un proxi de línea de costa que se pueda reconocer en las fotografías aéreas o imágenes satelitales. El método de cálculo de distancia es muy utilizado, lo que permite su comparación con otros casos de estudio y resulta de fácil comprensión para los tomadores de decisiones, no obstante, solo ofrece una dimensión de análisis. Con base en las fuentes de información disponibles y la escala espacio temporal de análisis seleccionada, en este estudio se optó por el cálculo de superficies.

\section{Área de Estudio}

Costa Rica se ubica en América Central, cuenta con costas en el Océano Pacífico y en el Mar Caribe. La costa Caribe tiene una extensión aproximada de $220 \mathrm{~km}$, casi cinco veces menor que la costa Pacífica (Vargas, 2006) debido, por un lado, a las fronteras establecidas con Nicaragua al norte y con Panamá al Sur, así como a una configuración más rectilínea de la costa Caribe. Por otro lado, el clima en el Caribe se caracteriza por no presentar una estación seca definida, mostrando dos periodos en que disminuyen las precipitaciones, el primero de febrero a marzo y el segundo entre setiembre y octubre (IMN, 2017). Herrera (1986) clasifica el clima del Caribe Sur como húmedo caliente con estación seca corta.

En cuanto a las mareas, la costa Caribe presenta una condición micromareal donde las mareas raramente superan $\operatorname{los} 30 \mathrm{~cm}$ (Murillo, 2001). El oleaje normalmente proviene del noreste con períodos promedio de ola de $7.38 \mathrm{~s} \mathrm{y}$ un carácter marcadamente local, con mayor energía durante los últimos y los primeros meses del año y menor de setiembre a octubre cuando disminuyen los vientos alisios (Lizano, 2007). Las principales corrientes a lo largo de la costa discurren de noroeste a sureste, como parte de la denominada circulación ciclónica del Giro Panamá-Colombia (GPC) (Andrade et al., 2003). 
Desde un punto de vista geológico y geomorfológico, la costa Caribe puede dividirse en dos sectores, el norte y el sur. La sección norte presenta características de un margen continental pasivo y un régimen tectónico extensivo (fallas normales) mientras que el sur presenta un régimen compresivo con ocurrencia de terremotos importantes (Alvarado \& Cárdenas, 2016). Geomorfológicamente, el sector norte muestra una configuración relativamente recta, con presencia de playas arenosas, barras de arena, lagunas costeras y un sistema de canales artificiales. La sección sur, por su parte, se caracteriza por la proximidad del sistema montañoso a la costa; entre Puerto Limón y Puerto Viejo se localizan playas arenosas extensas, no obstante, a partir de ésta última localidad, a la línea de costa se vuelve más intrincada, las playas se acortan hasta desarrollar playas de bolsillo o de herradura (pocket beaches), y se intercalan con costas rocosas (Figura 1).

La costa del Caribe Sur contrasta con la uniformidad de la costa Caribe Norte. La costa alterna entre áreas donde las llanuras costeras tienen una considerable extensión, con otras en las que las colinas de hasta $100 \mathrm{~m}$ llegan casi hasta el mar (Battistini \& Bergoeing, 1984). Se presentan promontorios rocosos que están asociados a un complejo arrecifal atribuido al Pleistoceno medio, conocido como Formación Puerto Viejo, que posee afloramientos rocosos en Puerto Limón, Cahuita y Puerto Viejo, así como a lo largo de las costas rocosas que se presentan entre Puerto Viejo y Punta Mona. De acuerdo con Battistini \& Bergoeing (1984), se trata de macizos de coral que alternan con brechas coralinas, así como con antiguos lechos de playa fosilizados (areniscas negras). Dicho complejo sobreyace en algunos sectores como Limón una formación similar denominada Portete, de edad Pleistoceno inferior. Los sectores rocosos de costa, además, presentan plataformas arrecifales expuestas o situadas en o cerca del nivel del mar actual, y que llegaron a esta posición debido al terremoto de Limón de 1991; por detrás de estas plataformas, recientemente levantadas, es frecuente encontrar otras terrazas, de entre 2 y $4 \mathrm{~m}$ sobre el nivel del mar actual, que pueden haberse formado por terremotos anteriores al del 91, aunque en su actual localización también pueden haber influido los movimientos eustáticos cuaternarios (Denyer, et al., 1994). Además, en sectores como Cahuita y Manzanillo, especialmente, encontramos extensas plataformas arrecifales sumergidas actuales. 
Figura 1. Área de Estudio

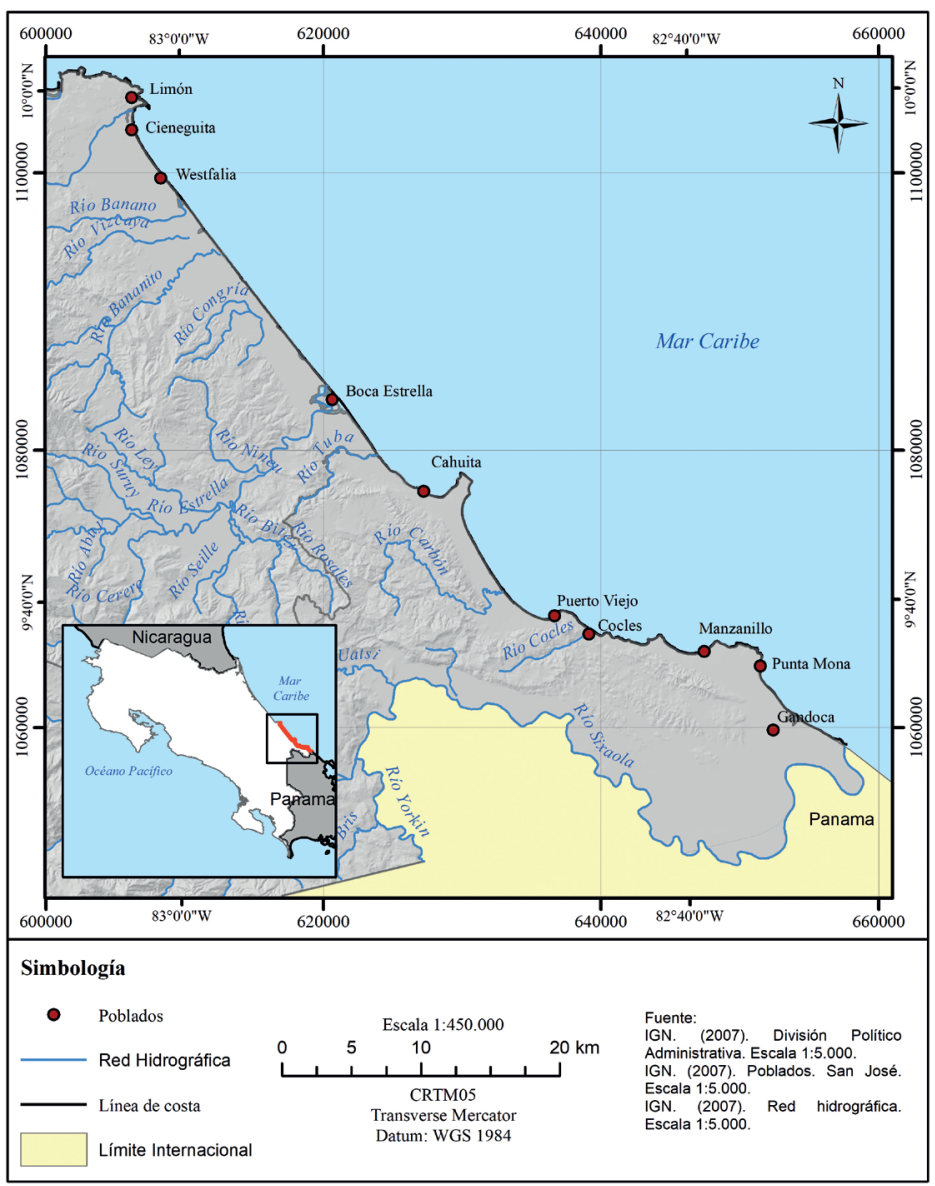

Fuente: elaboración propia

Administrativamente, la costa del Caribe Sur se encuentra entre los municipios de Limón y Talamanca, que ocupan respetivamente la posición 74 y 62 de los 81 cantones que forman el país en el Índice de pobreza Humana y la posición 73 y 80 en el Índice de Desarrollo Humano, para el 2011 (PNUD, 2013), lo que revela un rezago en el desarrollo de la región y problemas sociales agravados por la falta de fuentes de empleo. Las principales actividades económicas de la zona son el turismo de playa y naturaleza, la actividad portuaria y las plantaciones de banano. 


\section{Metodología}

La metodología utilizada se basa en el cambio de posición de la línea de costa, entendiendo esta como el límite preciso entre la tierra y el mar. A pesar de que su trazo se realiza usualmente siguiendo el nivel medio del mar, por la dificultad que representa identificar dicho nivel en el terreno, se utilizó como indicador el límite de la vegetación sobre la playa, alternado con el lado hacia el mar de las estructuras humanas en la costa cuando no es posible utilizar el primer criterio (Moore, 2000), un proxi recomendado cuando se desea enfatizar en la erosión de playas (Boak \& Turner, 2005).

Como fuentes de información para esta investigación, se utilizaron fotografía aéreas e imágenes de satélite. Para cumplir con el objetivo de establecer tasas de erosión costera, se debieron seleccionar aquellas secuencias de fotografía que cubrían un área a gran escala y que contaran con procesos de ortorectificación. Donde las fotografías aéreas existentes entre 1956 y 1993 no fueron utilizadas debido a las variaciones de sus escalas (la mayoría entre 1:60 000 y 1:40 000) o a la inexistencia de los parámetros de calibración de la cámara, necesarios para la realización de procesos de ortorectificación, lo que las hace una fuente inapropiada para un enfoque cuantitativo (Thiele \& Danforth, 1994; Moore, 2000), como el que se utiliza en este trabajo.

Siguiendo estos criterios, se seleccionó un mosaico de ortofotos a escala 1:5 000 del año 2005 (con una resolución espacial de $0,5 \mathrm{~m}$ por píxel) que fue encargado por el Registro Nacional y avalado por el Instituto Geográfico Nacional (IGN). Del mismo modo, se eligieron las orto-fotografías aéreas del año 2016, que contrató la Comisión Nacional de Prevención de Riesgos y Atención de Emergencias (CNE) como parte de un levantamiento LiDar de la zona costera, a escala 1:1 000 (con resolución espacial de $0,1 \mathrm{~m}$ ). Por la extensión de tiempo que representa el periodo entre 2005 y 2016 y con la intención de evaluar las tendencias temporales con mayor detalle, se adquirieron seis imágenes pancromáticas de satélite de muy alta resolución espacial $(0,5$ y $0,6 \mathrm{~m})$ con ortorectificación rigurosa, para cubrir el año 2010 a escala 1:5 000 .

Una vez definidas las fuentes de datos se procedió con la digitalización de las líneas de costa para los años 2005, 2010 y 2016, por medio del uso de un Sistema de Información Geográfico (SIG). Para la homogenización de los productos obtenidos se definió la escala 1:1 000 para la 
digitalización de dichas líneas. Lo anterior permitió el establecimiento de dos periodos de análisis para su comparación, 2005 a 2010 y 2010 a 2016.

Posteriormente, se clasifican los cambios de posición de estas líneas como avance, retroceso y estabilidad. El primer caso se presenta cuando la línea de costa avanza hacia el mar entre el año inicial y el final; el segundo cuando la línea retrocede hacia tierra entre el año inicial y el final, y el último cuando las líneas del año inicial y final registran poco cambio entre ellas. En las playas donde se encontró un mayor retroceso de la línea de costa, se procedió a estimar la tasa de retroceso areal ( $\left.\mathrm{m}^{2} / \mathrm{año}\right)$ (Ojeda, 2000), tanto para el periodo 2005-2010, como para el periodo 2010-2016. De esta forma fue posible determinar si la tendencia observada en la primera serie temporal se mantiene, aumentó o disminuyó en el segundo periodo. Una vez calculada la tasa se realiza una verificación de campo, para comprobar si el resultado encontrado por medio de técnicas de fotointerpretación se corresponde con un proceso acelerado de erosión de playa.

\section{Resultados}

Para facilitar la interpretación de los resultados obtenidos, la costa fue dividida en seis áreas atendiendo a la configuración de la costa (Figura 2), estas son:

- Cieneguita-Westfalia: sector ubicado al extremo noroeste, caracterizado por presentar una playa extensa con una ligera concavidad hacia el mar, en dirección al norte, principalmente, en el sector más próximo al promontorio rocoso donde se asienta la ciudad de Limón. La playa de Cieneguita presenta un espigón hacia la mitad de la misma.

- Westfalia-Cahuita: se presenta como una costa rectilínea con presencia de desembocaduras de importantes sistemas fluviales y humedales en sus alrededores (esteros).

- Cahuita: se trata de una pequeña península en la que encontramos dos sectores en los que aflora la plataforma rocosa arrecifal intercalada por una playa arenosa (Playa Blanca de Cahuita); sobre el sector de plataforma más pequeño se encuentra la población del mismo nombre, y sobre el otro la Punta Cahuita propiamente. Tanto la playa como la Punta son parte de un área protegida (Parque Nacional 
Cahuita). Entre las principales características del parque está la presencia de un importante arrecife coralino actual.

- Puerto Vargas-Puerto Viejo: desde el antiguo atracadero conocido como Puerto Vargas hasta la localidad de Puerto Viejo se extiende un litoral rectilíneo a ligeramente cóncavo hacia el mar Caribe, interrumpido únicamente por la desembocadura del río Carbón.

- $\quad$ Puerto Viejo-Punta Mona: zona compuesta por playas relativamente cortas y pocket beaches intercaladas con salientes, promontorios rocosos y afloramientos de las formaciones arrecifales del Pleistoceno, en forma de terrazas.

- Punta Mona-Sixaola: litoral rectilíneo interrumpido por antiguas desembocaduras y humedales; solamente el sector inicial de Punta Mona es rocoso. Finaliza en el extremo sur de Costa Rica, en la desembocadura del río Sixaola, en correspondencia de la frontera con Panamá.

Figura 2. Zonas para el análisis de la erosión de playas en el Caribe Sur

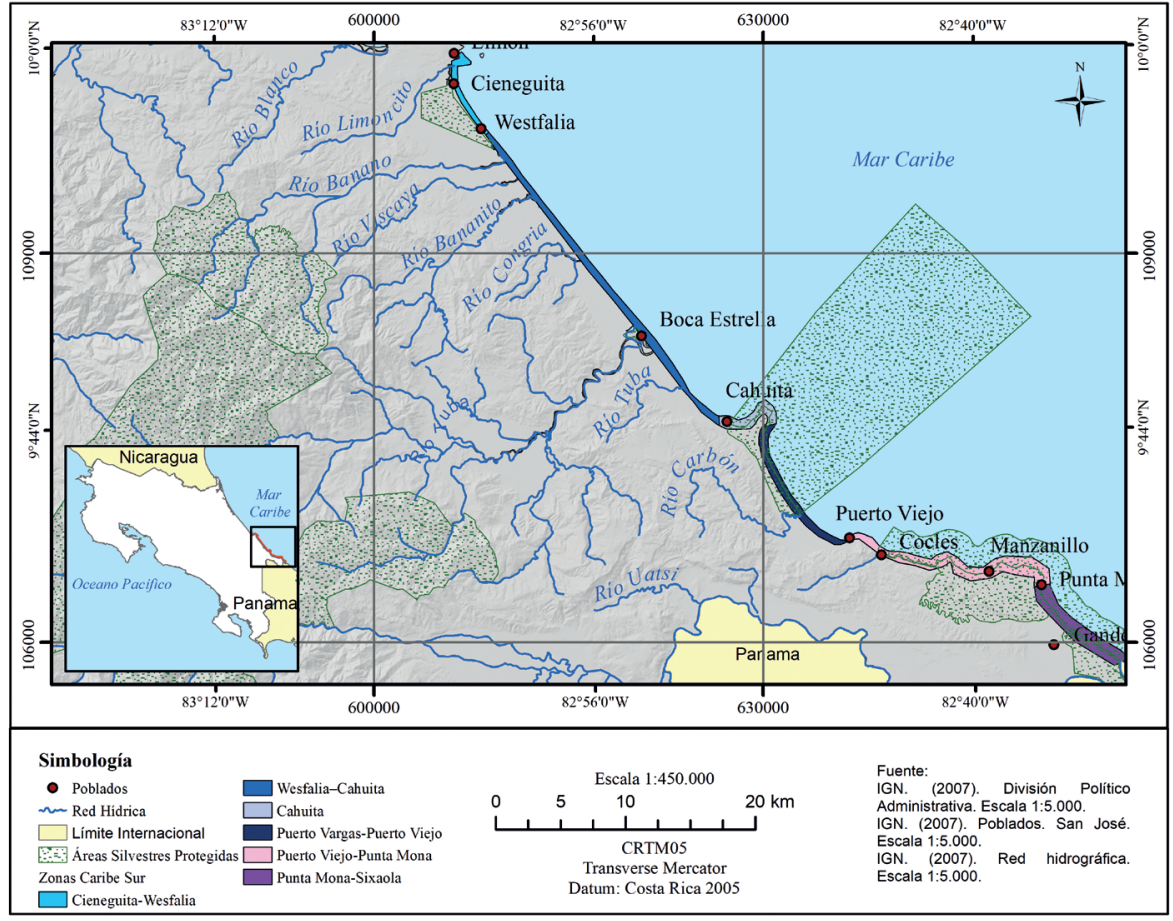


Los cambios en la línea de costa registrados entre los periodos 2005 - 2010 y 2010 - 2016 revelaron 11 puntos calientes de erosión costera en el Caribe Sur de Costa Rica, los mismos se presentan a continuación en cada zona establecida:

\section{Cieneguita-Westfalia}

Al norte de esta sección se encuentra un área urbanizada llamada Barrio Cieneguita, denominada oficialmente como sector Cristóbal Colón, y al sur, el aeropuerto de Limón (Figura 3.b). Este sector está influenciado por la presencia de un importante humedal que se localiza tierra adentro; se trata de un área protegida denominada Refugio de Vida Silvestre Limoncito. El retroceso de la línea de costa es más evidente al sur del espigón (Figura 3.a), un área donde la deriva litoral de sedimentos fue cortada por la construcción de dicha obra. Al sur de la línea de costa alcanza ya las infraestructuras humadas colocadas en la costa (acera, ciclovía y alumbrado público).

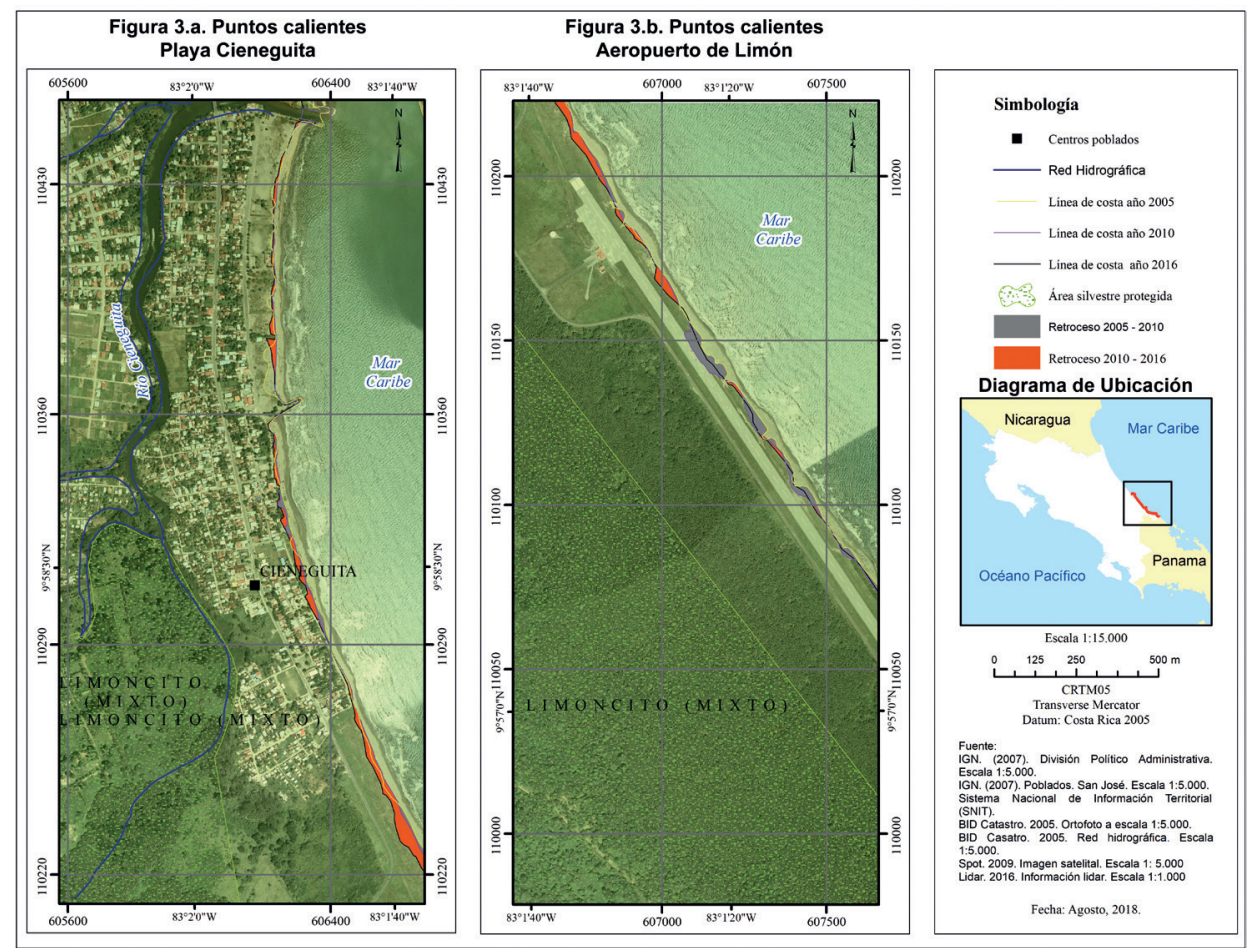


El sector entre el espigón hasta la pista de aterrizaje se considera un punto caliente de erosión donde se registra una tasa de retroceso de 1430 $\mathrm{m}^{2}$ /año para el periodo 2005-2010 y de $3936 \mathrm{~m}^{2} /$ año para el periodo 20102016. De acuerdo con estos datos la tasa de retroceso casi se triplicó en el segundo periodo (Figura 3.a). Este retroceso apunta a un proceso de erosión que se constató en el trabajo de campo, donde se encontró afectación sobre la infraestructura pública y la consecuente realización de obras para contenerlo, como la colocación de piedras y mallas (Figuras 4 y 5).

Figura. 4. Colocación de cantos rodados en Playa Cieneguita para proteger la infraestructura pública.

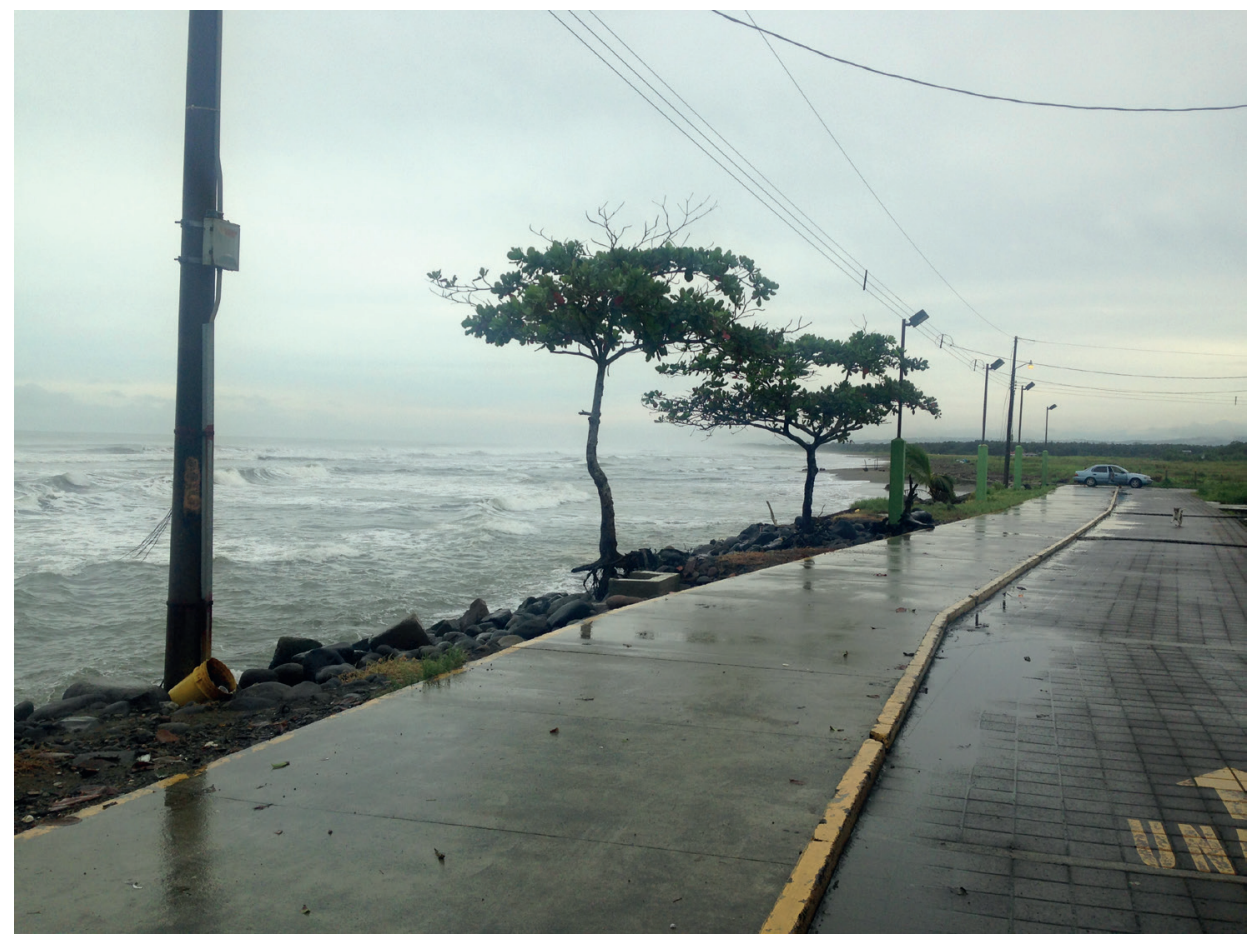

Fuente: Tomada por G. Barrantes, 2017. 
Gustavo Barrantes-Castillo - Isabel Arozarena-Llopis

Luis Fernando Sandoval-Murillo - José Francisco Valverde-Calderón

Critical beaches due to coastal erosion in the Caribbean south of Costa Rica during the period 2005-2016

Figura 5. Revestimiento pedregoso con malla para proteger la calzada en Playa Cieneguita.

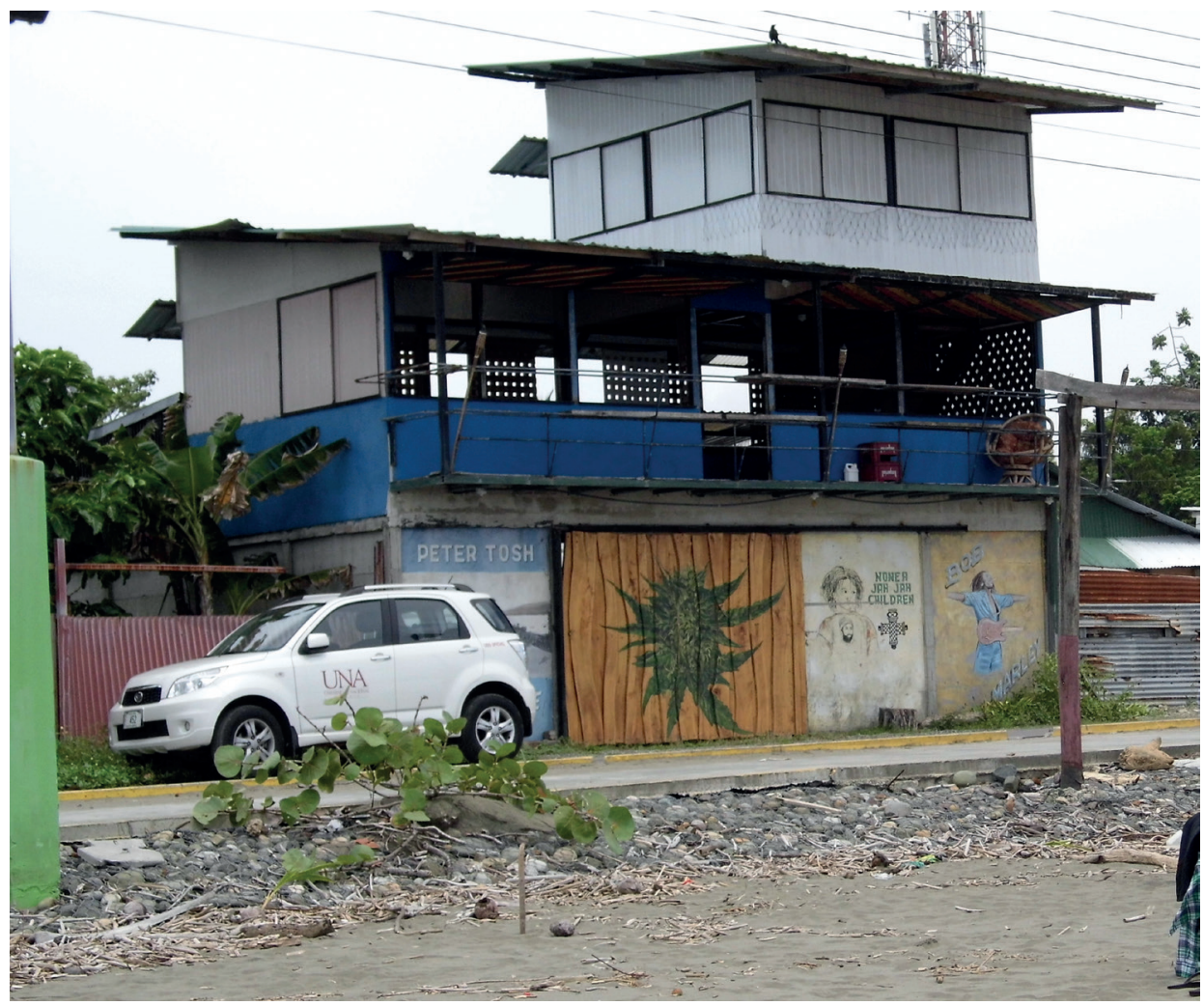

Fuente: Tomada por G. Barrantes, 2017.

Otro punto caliente de erosión se encuentra en las proximidades del aeropuerto (Figura 3.b). Para el periodo 2005-2010, la tasa de erosión de este sector fue de $8801 \mathrm{~m}^{2} /$ año y para el periodo 2010-2016 se redujo a 1 $599 \mathrm{~m}^{2} /$ año. Al sur del aeropuerto se encuentra un humedal caracterizado por la presencia de pequeños lagos elongados, interconectados por canales que desaguan antes de alcanzar el poblado de Westfalia, lo que evidencia que se trata de una alteración de parte del humedal de Cieneguita. La erosión de la playa ha afectado la capa asfáltica de la pista; para su protección se ha colocado un revestimiento de rocas con malla (Figura 6). 
Figura 6. Revestimiento pedregoso con malla a un costado de la pista de aterrizaje donde la erosión ha obligado a proteger la obra.

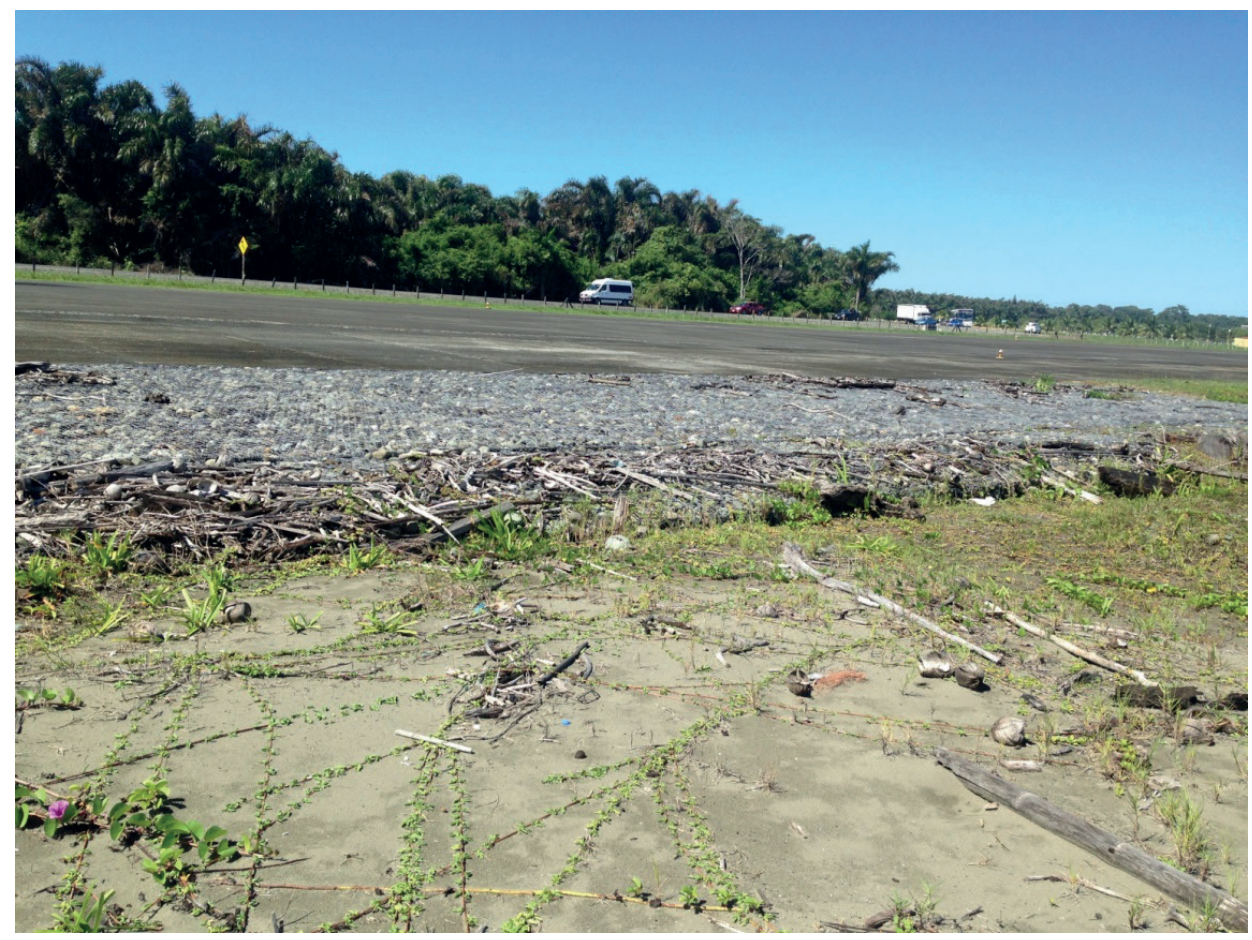

Fuente: Tomada por G. Barrantes, 2017.

\section{Sector Westfalia-Cahuita}

Se trata de un sector con playas extensas intercaladas con desembocaduras de importantes sistemas fluviales (Figura 2). La dinámica litoral se manifiesta en drásticos cambios en la forma de la línea de costa debido, principalmente, por la migración de las desembocaduras. En este sector sobresalen los cambios en la desembocadura del río Banano (Figura 7.a, arriba a la izquierda), lo que originó un retroceso local de la línea de costa asociado con la erosión de la margen izquierda de la desembocadura y la acumulación de sedimentos en la margen derecha. Otras desembocaduras con importantes cambios son la del río Vizcaya, río Bananito y río La Estrella (Figura 7.b,7.c y 7.d respectivamente). 
Gustavo Barrantes-Castillo - Isabel Arozarena-Llopis

Luis Fernando Sandoval-Murillo - José Francisco Valverde-Calderón

Critical beaches due to coastal erosion in the Caribbean south of Costa Rica during the period 2005-2016

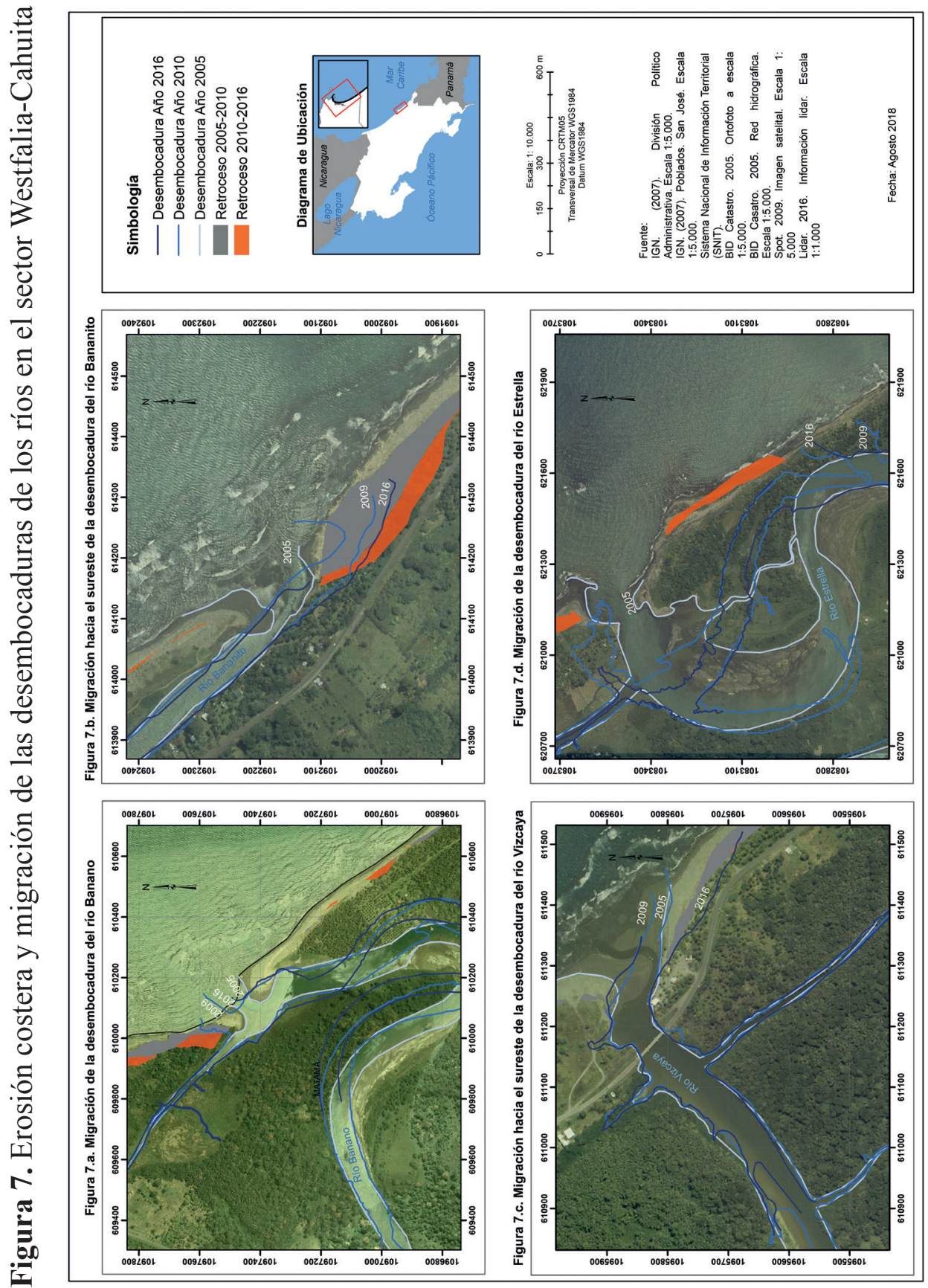


El primer punto caliente de este sector se localiza al sur del poblado de Westfalia, asociados con la migración de la desembocadura del rio Banano (Figura 8). En esta sección la línea de costa ha experimentado una tasa de erosión de $4842 \mathrm{~m}^{2} /$ año en el periodo 2005-2010, monto que aumento a $6471 \mathrm{~m}^{2} /$ año entre el 2010-2016, lo que representa un aumento de la velocidad del proceso.

Figura 8. Punto caliente localizado al sur del poblado de Westfalia.

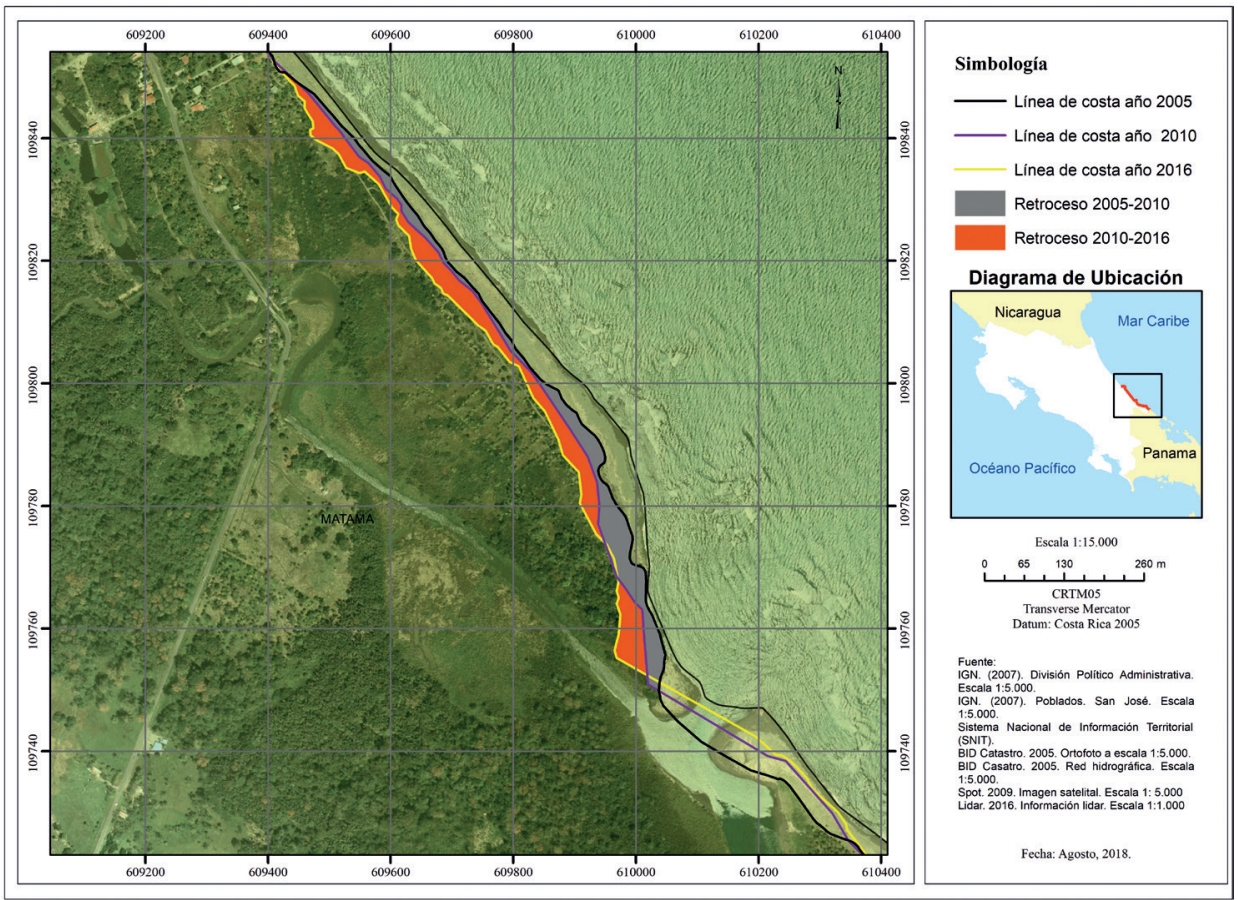

Otro punto crítico de erosión se localizó en la desembocadura del río Bananito (Figura 7.a), donde al igual que en los casos anteriores, está ligado a la migración del cauce. En este caso la proximidad de la línea de costa con la carretera resulta en una amenaza para la carretera principal que da acceso al resto de la región (figura 9). La tasa de erosión en este punto es de $2817 \mathrm{~m}^{2} /$ año en el periodo $2005-2010$ y de $2793 \mathrm{~m}^{2} /$ año entre el 2010 2016, lo que indica que la tasa se mantiene similar entre los dos periodos. 
Figura 9. Proximidad de la carretera con la zona de erosión de playa.

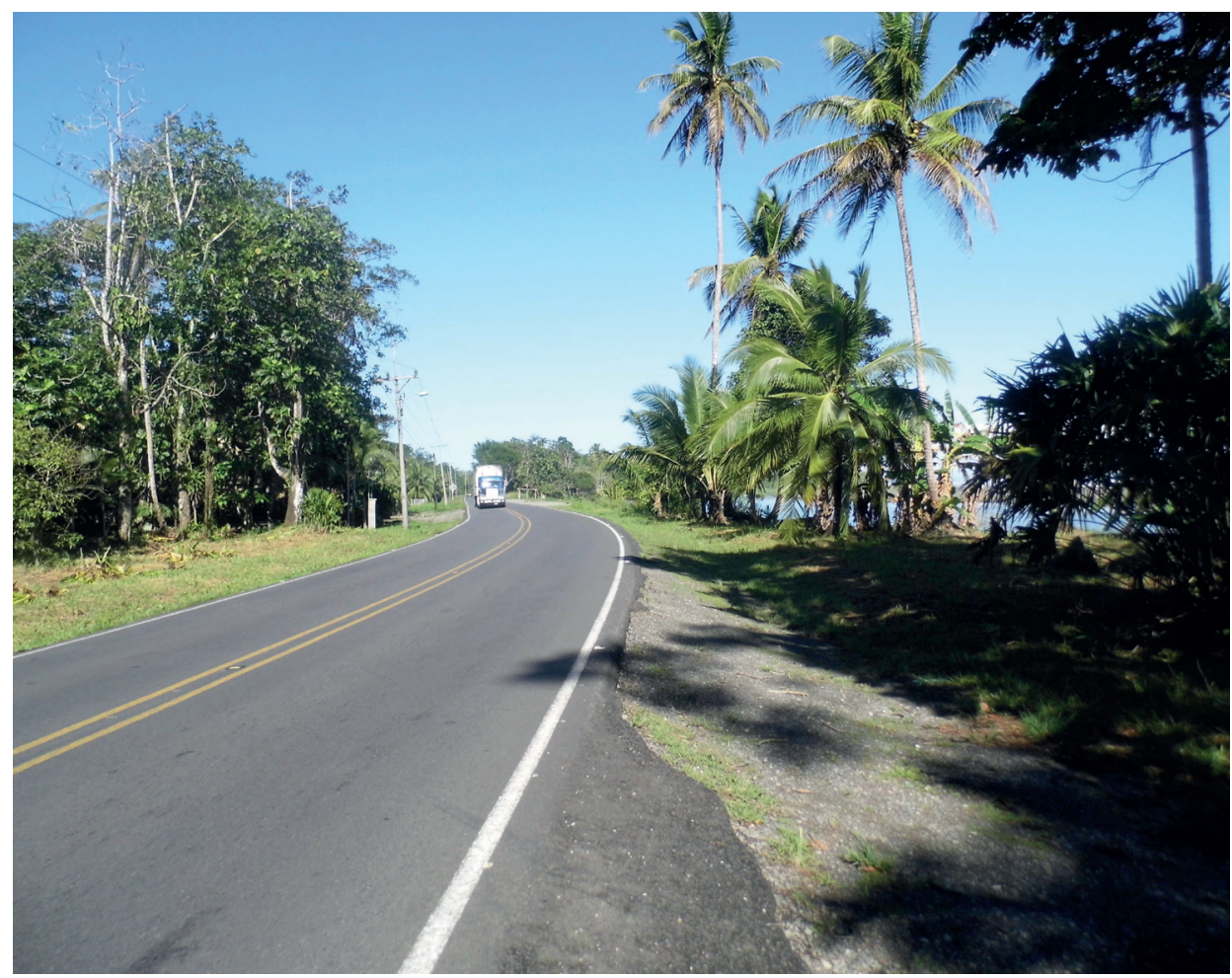

Fuente: Tomada por G. Barrantes, 2017.

\section{Sector Cahuita}

Este sector se caracteriza por la presencia de promontorios rocosos relacionados con una antigua paleo-plataforma coralina descrita por Battistini \& Bergoeing (1984), así como por la presencia de coral vivo frente a la punta, que se encuentra protegido por la existencia del Parque Nacional Cahuita (Figura 2).

El primer punto de erosión acelerada se encuentra propiamente dentro del Parque Nacional, específicamente en el sector conocido como Cahuita (Figura 10.a). En este sector del parque el retroceso de la línea de costa para el periodo 2005-2010 fue de $1300 \mathrm{~m}^{2} /$ año, valor que se incrementa a $4598 \mathrm{~m}^{2}$ /año entre el 2010 -2016. Estos valores muestran que la tasa de erosión se triplicó en el periodo más reciente. 
El otro punto caliente de esta área se localiza al otro sector de Punta Cahuita, conocida como Puerto Vargas (Figura 10.b). En este punto la tasa de erosión fue de $2480 \mathrm{~m}^{2}$ /año en el periodo 2005-2010, pasando a $9510 \mathrm{~m}^{2} /$ año en el periodo 2010-2016. En este punto, al igual que en el anterior la tasa se triplicó entre un periodo y el otro. Este incremento se evidencia a lo largo del sendero de acceso al sector donde se encontraba el antiguo Puerto Vargas.

Figura 10. Puntos calientes localizados en el Parque Nacional Cahuita.

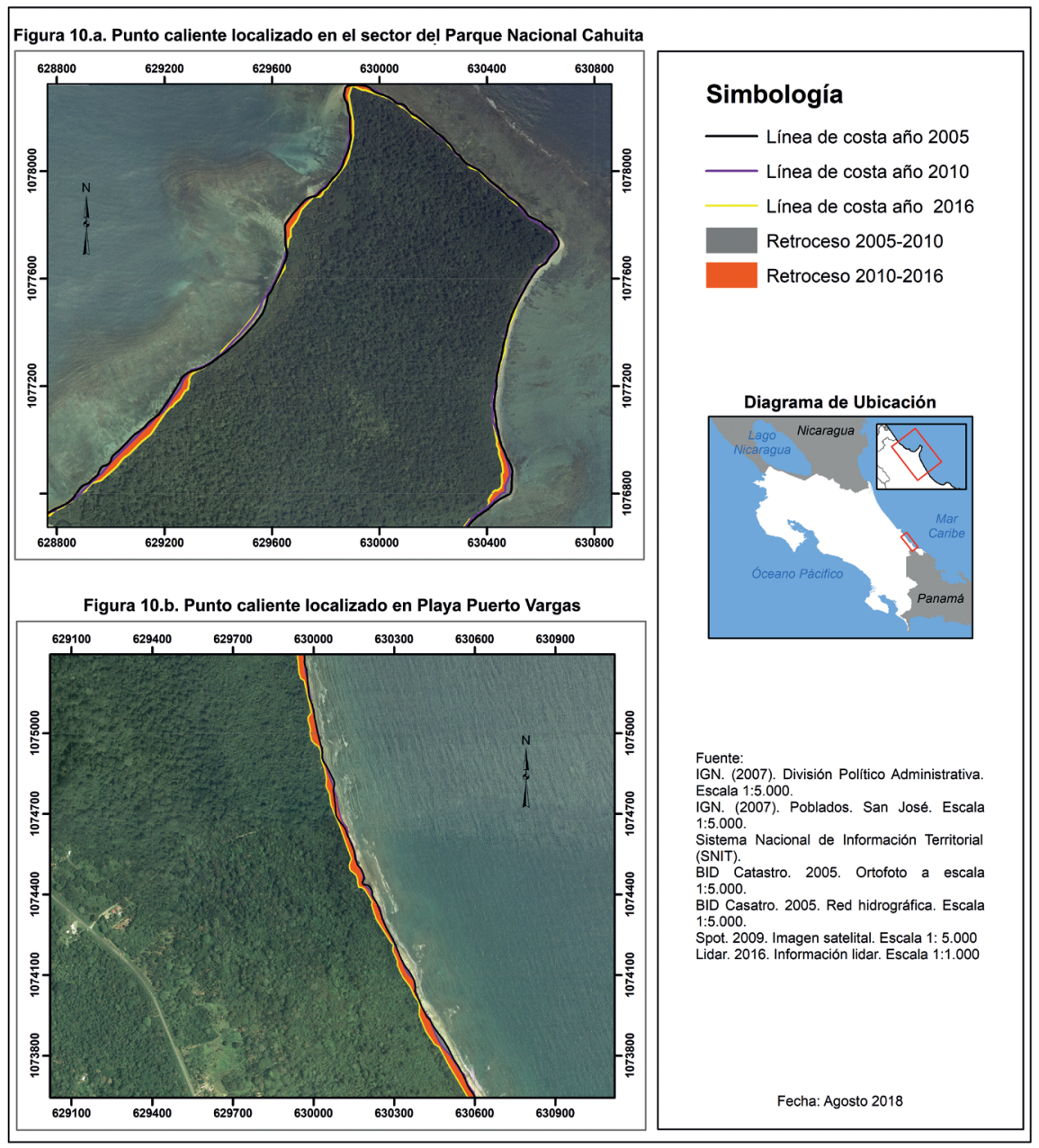


En los puntos anteriores es notable que la presencia de un extenso arrecife actual, considerado el más grande de Costa Rica (Cortés et al., 2010), no parece representar una protección natural contra la erosión, a pesar de abrigar la costa frente a los puntos críticos de esta sección. Es posible que las variaciones locales de profundidad, junto con la presencia de canales rocosos, puedan crear refracciones del oleaje y una redistribución de las corrientes de deriva, lo que parcialmente explicaría la presencia de estos dos puntos calientes de erosión.

\section{Sector Puerto Vargas-Puerto Viejo}

Se trata de una extensa playa que inicia al sur de Punta Cahuita y finaliza en playa Negra de Puerto Viejo, antes del poblado del mismo nombre (Figura 2). En este sector se localiza un punto caliente en los alrededores de la calle de acceso al sector Puerto Vargas del Parque Nacional Cahuita que se extiende hacia el sur de la misma (Figura 10.b), a pesar de no localizarse dentro del parque a diferencia de la zona anterior, estas playas no están protegidas del oleaje por el arrecife coralino.

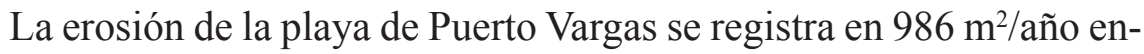
tre 2005-2010, este valor se incrementa notablemente entre el 2010-2016, alcanzando una tasa de $8953 \mathrm{~m} 2 /$ año, lo que representa un aumento de nueve veces la tasa del periodo anterior.

\section{Puerto Viejo-Punta Mona}

En este sector encontramos playas de bolsa y algunas más extensas, como playa Cocles, alternando con sectores más rocosos, en los que afloran las formaciones arrecifales del Pleistoceno, y cerca del nivel del mar el arrecife levantado en el terremoto de 1991. También, bajo el agua, aparecen parches de arrecife actual. Casi toda el área se localiza dentro del Refugio Natural de Vida Silvestre Gandoca-Manzanillo, bajo un modelo de administración mixto (estatal y privado) (Figura 2).

La Playa Manzanillo se ubica frente a un el arrecife que es considerado por Cortés et al. (2010) como una incipiente cresta de algas; de acuerdo con estos autores, para el 2003 el coral vivo abarcaba apenas un $7 \%$ de su extensión. Al igual que en el caso de los puntos anteriores, la tasa de erosión de la playa se registra moderada en el periodo 2005-2010, 
alcanzando un valor de $745 \mathrm{~m}^{2} /$ año, que se incrementa a $1678 \mathrm{~m}^{2} /$ año entre el 2010-2016, lo que representa un aumento de más del doble (Figura 11).

Figura 11. Punto caliente de erosión localizado en las proximidades del poblado de Manzanillo

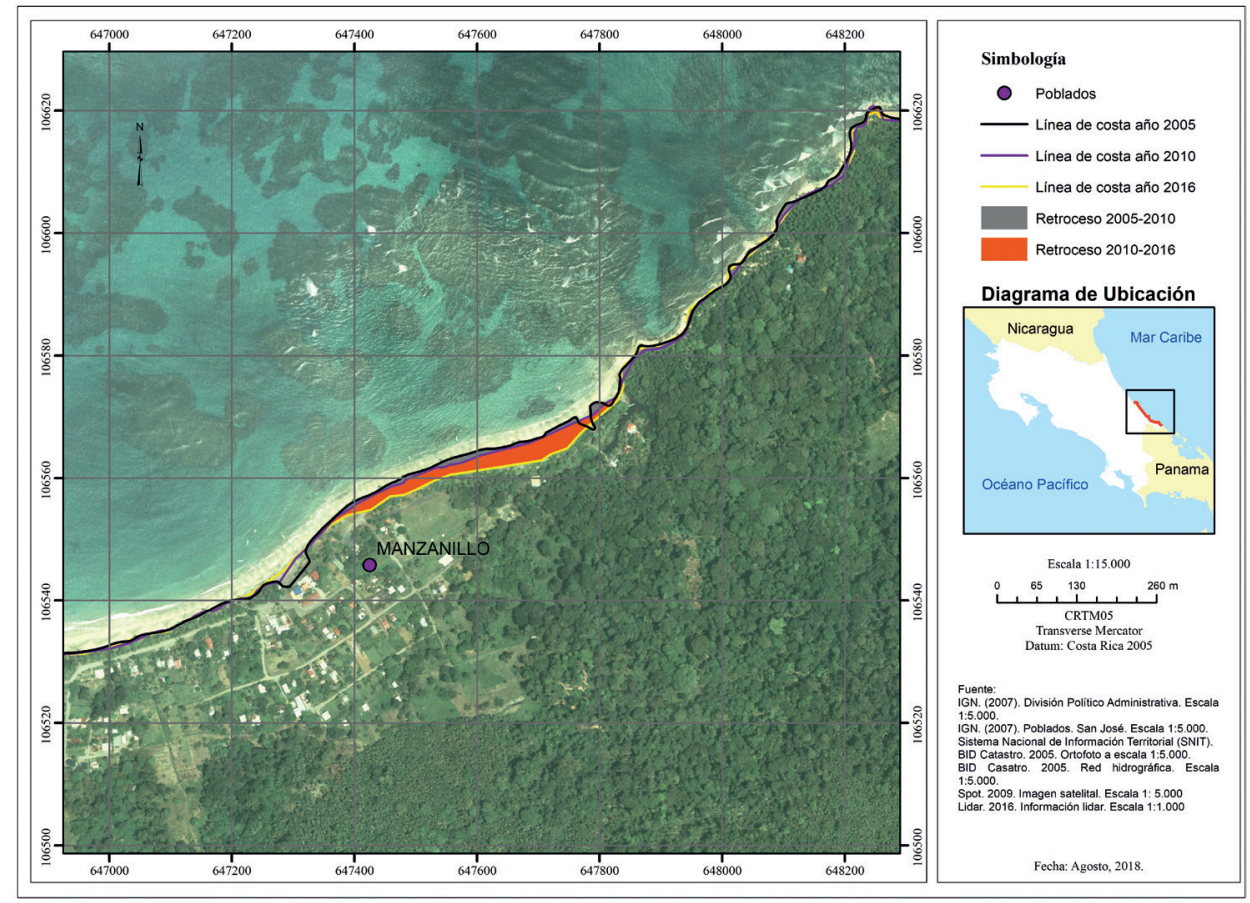

\section{Punta Mona-Sixaola}

Se trata de una extensa playa convexa hacia el mar que es interrumpida por desembocaduras actuales y antiguas que se mantienen actualmente como humedales (Figura 2). La zona incluye dos largas playas: Mile Creek y Gandoca. En esta zona se encuentra el poblado de Gandoca que presenta una baja densidad de población.

En el sector se han localizado tres puntos calientes, el primero en el sector de playa Mile Creek o quebrada Milla (Figura 12.a). En este caso, la 
zona de retroceso de la línea de costa se encuentra extendida a lo largo de la playa. Para el periodo 2005-2010 la tasa de erosión correspondía a 626 $\mathrm{m}^{2} / \mathrm{año}$, valor que aumentó en más de 7 veces en el periodo 2010-2016, pasando a alcanzar una tasa de $4865 \mathrm{~m}^{2} /$ año.

El segundo punto se encuentra próximo a la carretera de acceso a playa Gandoca (Figura 12.b). Se trata de un área pequeña donde, al igual que en el caso anterior, la erosión era menor para el periodo 2005-2010 con una tasa de $1194 \mathrm{~m}^{2} /$ año, que se incrementó tres veces para el periodo 2010-2016, hasta llegar a un valor de $3642 \mathrm{~m}^{2} /$ año.

Figura 12. Puntos calientes localizados en el sector Punta Mona-Sixaola

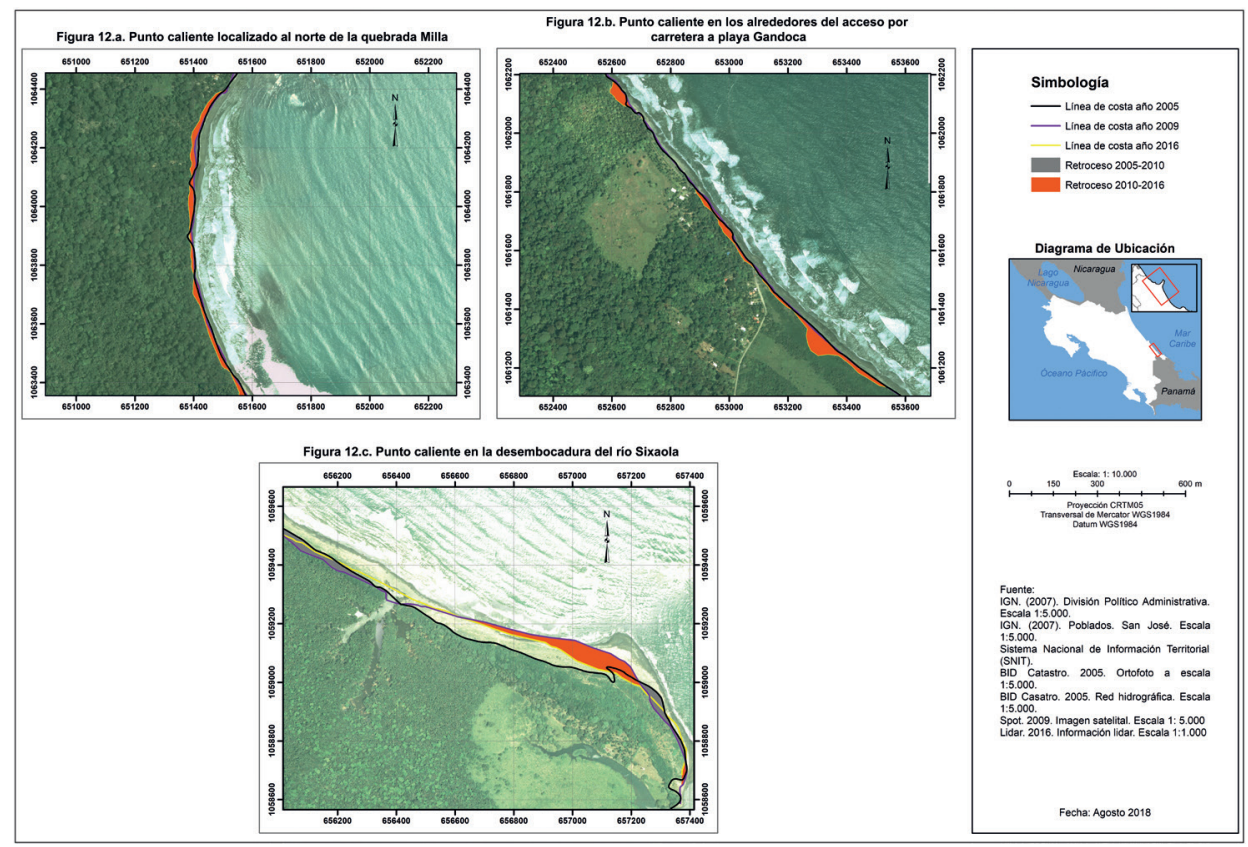

El último sector de esta área es la playa que se encuentra entre la laguna de Gandoca y el río Sixaola (Fig. 12.c), en este punto la erosión alcanzó una tasa de $1697 \mathrm{~m}^{2} /$ año en el periodo 2005-2010, valor que se incrementó más de cuatro veces para el periodo 2005-2016, alcanzando una tasa de $7456 \mathrm{~m}^{2} /$ año. 


\section{Discusión de resultados}

Se realizó una división de la línea de costa como marco de análisis para los procesos de erosión acelerada en las playas en el Caribe Sur de Costa Rica, definidos a partir de características geomorfológicas similares. En todos los sectores definidos se encontraron puntos calientes de erosión costera. En consecuencia, el retroceso de la costa se presenta en playas extensas rectas y cóncavas, con presencia de desembocaduras, playas cortas entre promontorios rocosos (pocket beaches), e incluso en zonas protegidas del oleaje directo por arrecifes de coral. Lo anterior lleva a concluir que en el Caribe Sur de Costa Rica se está experimentando un proceso extendido de erosión costera que se manifiesta en once puntos críticos a lo largo de la costa.

Las playas que han experimentado la mayor pedida de área, para el periodo 2005-2016, fueron: El sector próximo al antiguo Puerto Vargas (71 $924 \mathrm{~m}^{2}$ ), Westfalia $\left(63038 \mathrm{~m}^{2}\right)$, la playa de Puerto Vargas al sur del antiguo puerto $\left(58.650 \mathrm{~m}^{2}\right)$ y la playa Bananito, al sur de la desembocadura del río del mismo nombre (53 $\left.599 \mathrm{~m}^{2}\right)$.

En el Tabla 2 y 3 se resumen las playas que experimentaron la mayor tasa de erosión, en los dos periodos analizados.

Tabla 2. Playas con mayor tasa de erosión en los periodos 2005-2010

\begin{tabular}{|l|c|c|}
\hline \multicolumn{1}{|c|}{ Localidad } & Tasa & Periodo \\
\hline Aeropuerto de Limón & $8801 \mathrm{~m}^{2} /$ año & $2005-2010$ \\
\hline Westfalia & $4842 \mathrm{~m}^{2} /$ año & $2005-2010$ \\
\hline Puerto Varga en punta Cahuita & $2972 \mathrm{~m}^{2} /$ año & $2005-2010$ \\
\hline Desembocadura del río Bananito & $2817 \mathrm{~m}^{2} /$ año & $2005-2010$ \\
\hline
\end{tabular}

Fuente: elaboración propia 
Tabla 3. Playas con mayor tasa de erosión en los periodos 2010-2016

\begin{tabular}{|l|c|c|}
\hline \multicolumn{1}{|c|}{ Localidad } & Tasa & Periodo \\
\hline Puerto Vargas en Punta Cahuita & $9510 \mathrm{~m}^{2} / \mathrm{año}$ & $2010-2016$ \\
\hline $\begin{array}{l}\text { Playa Puerto Vargas al sur del } \\
\text { antiguo puerto }\end{array}$ & $8953 \mathrm{~m}^{2} / \mathrm{año}$ & $2010-2016$ \\
\hline $\begin{array}{l}\text { Playa Gandoca hasta la } \\
\text { desembocadura del río Sixaola }\end{array}$ & $7456 \mathrm{~m}^{2} / \mathrm{año}$ & $2010-2016$ \\
\hline Westfalia & $6471 \mathrm{~m}^{2} / \mathrm{año}$ & $2010-2016$ \\
\hline
\end{tabular}

Fuente: elaboración propia

El mayor incremento en las tasas de erosión para el periodo 2010 2016, con respecto al periodo anterior 2005 - 2010, se presentó en Cahuita, específicamente en el sector Puerto Vargas, seguido por Gandoca en la playa de Mile Creek y entre la Laguna de Gandoca y la desembocadura del río Sixaola. Contrariamente, las playas donde se redujo la tasa de erosión fueron Bananito y Aeropuerto (Tabla 2 y 3 ).

A pesar de que en esta investigación no se realizan análisis correlacionales, es posible analizar algunas posibles causas de la presencia y aumento de procesos de erosión en la costa Caribe Sur de Costa Rica. En primer lugar, la presencia de edificaciones sobre la línea de costa, parece explicar la erosión encontrada únicamente en Playa Cieneguita, por la presencia de un espigón que, según la evidencia que se encuentra en las fotografía aéreas y el estudio a detalle de la evolución de las líneas de costa en este sector, realizado por Barrantes et al., (2017), explicaría la erosión acelerada que se presenta al sur de la obra, proceso que puede estar afectando inclusive el punto localizado en los alrededores del aeropuerto de Limón. En las demás playas no se encuentran edificaciones que alteren sustantivamente la distribución de los sedimentos por deriva litoral o las condiciones del oleaje.

En cuanto al suministro de sedimentos por parte de los ríos, estos no han experimentado la construcción de embalses que limiten su transporte a la costa. A pesar de que se han realizado dragados para mitigar las inundaciones, éstos resultan puntuales en el tiempo y el espacio, por lo que su impacto es reducido.

Del mismo modo, no se han experimentado cambios significativos en el uso del suelo, que puedan modificar la disponibilidad de sedimentos. 
No obstante, al igual que el país, las cuencas hidrográficas que desembocan en esta zona ha experimentado un aumento de la cobertura forestal que puede estar causando una disminución del aporte de los sedimentos, sin que existan estudios al respecto.

En cuanto al aumento en el nivel del mar, BIOMARCC-SINAC-GIZ (2013) presenta tasas anuales de alrededor de $2 \mathrm{~mm} /$ anuales para la zona, valor que no difieren de la media mundial. Este aumento constante en el nivel de mar puede ser una de las causas del proceso de erosión. No obstante, la geodinámica local juega un papel de primer orden en la compensación de este efecto. En este sentido el levantamiento cosísmico, asociado con el Terremoto de Limón de 1991, provocó un levantamiento generalizado en la costa, proceso que favoreció el avance hacia el mar de la línea de cota. Actualmente, no se disponen de datos para evaluar la participación de la geodinámica local sobre el proceso de erosión costera.

En este sentido, la tectónica regional pueda estar jugando un papel en los procesos erosivos de la costa, similar al que juega en la costa de la Península de Nicoya. En este sector del Pacífico Norte, se alternan terremotos que levantan la costa, con períodos de aproximadamente 50 años, en los que se produce subsidencia en el litoral, debido al acople de las placas en una zona de subducción, y el consiguiente arrastre hacia debajo de la placa superior (Norabuena et al., 2004; M. Protti, F. Güendel, \& E. Malavassi, 2001). En el caso del Caribe Sur, también es conocida la periodicidad de los terremotos que levantan la costa (G. Alvarado \& G. Cárdenas, 2016, P. Denyer, O. Arias, \& S. Personius., 1994; J. S. Marshall, 2007). Aunque la geodinámica y tectónica de este margen caribeño no se corresponde propiamente con una zona de subducción tampoco se ha estudiado con detalle el mecanismo de acumulación de esfuerzos y subsidencia costera que podría existir en los periodos entre grandes sismos que levantan la costa, comportamiento que podrían contribuir a explicar los procesos de erosión acelerada descritos que, hasta el momento, no parecen tener una explicación clara.

Otras posibles variables explicativas se relacionan con la variabilidad climática, en particular los episodios de "El Niño", las fluctuaciones en las corrientes marinas locales, cambios en el patrón del oleaje relacionado con tormentas ciclónicas, para los cuales se tienen pocos datos que permitan evaluar su aporte al proceso. 


\section{Conclusiones}

Se identificaron 11 puntos calientes (hot spot) de erosión costera en el Caribe Sur. Estas playas se localizan en: Cieneguita, Aeropuerto de Limón, Westfalia, Boca Bananito, Playa Blanca de Cahuita, Puerto Vargas alrededor del antiguo puerto, Playa Puerto Vargas al sur de la carretera de acceso, Manzanillo, Mile Creek, Gandoca y Sixaola.

La ubicación de estos puntos calientes comprende los diferentes tipos de línea de costa descritos, según la delimitación utilizada, donde se incluyen: las playas rectas extensas expuestas al oleaje, con presencia de desembocaduras, pequeñas playas en herradura entre promontorios rocosos (pocket beaches), e incluso en zonas protegidas del oleaje directo por arrecifes de coral. Este hecho lleva a afirmar que se está presentando un proceso extensivo de erosión acelerada en el Caribe Sur de Costa Rica.

Las playas que experimentaron la mayor pedida de área, para todo el periodo de estudio (2005-2010) fueron: Westfalia, Puerto Vargas, y la playa de Puerto Vargas, al sur del antiguo puerto, y la playa Bananito, al sur de la desembocadura del río del mismo nombre. Así mismo, el mayor incremento en las tasas de erosión en el segundo periodo analizado (20102016) se registró en: Puerto Vargas, alrededor del antiguo puerto y en Gandoca. Contrariamente, las playas donde se redujo la tasa de erosión fueron Bananito y Aeropuerto.

Los procesos de erosión son evidentes en el campo, incluso han llevado a la construcción de obras de mitigación, entre las que destacan el revestimiento con rocas y la construcción de muros de piedras, que se han colocado para proteger el sector de playa de la comunidad de Cieneguita, el Aeropuerto de la región y la ruta nacional 36 próxima a la desembocadura del río Bananito.

\section{Referencias}

Alvarado, G. \& Cárdenas, G. (2016). Chapter 3 Geology, Tectonics, and Geomorphology of Costa Rica: A Natural History Approach. En M. Kappelle, Costa Rican Ecosystems (p. 744). London: University of Chicago Press.

Andrade, C. A., Barton, E. D. \& Mooers, C. N. (2003). Evidence for an eastward flow along the Central and South American Caribbean Coast. Journal of Geophysical Research: Oceans, 108(C6). 
Anthony, J. E. (2005). Beach erosion. En M. Schwartz, Encyclopedia of coastal science (pp. 140-145). Netherlands: Springer.

Barrantes, G., Valverde, J. F., Piedra, L., Quesada, A., Castillo, M., Sandoval, L., y otros. (2017). Cambios en la línea de costa en playa cieneguita, limón. $17^{\circ}$ Congresso Latino-Americano de Ciências do Mar (págs. 1212-1214). Balneário Camboriú, Brasil : Associação LatinoAmericana de Pesquisadores em Ciências do Mar.

Battistini, R. \& Bergoeing, J. P. (1984). Geomorfología de la Costa Caribe de Costa Rica. Revista Geográfica (99), 167-188.

BIOMARCC-SINAC-GIZ. (2013). Análisis de vulnerabilidad de las zonas oceánicas y marino-costeras de Costa Rica frente al cambio climático.San José.

Boak, E. H. \& Turner, I. L. (2005). Shoreline Definition and Detection: A Review. Journal of Coastal Research (214), 688-703.

Bosque, D. (14 de Febrero de 2016). Mar se come poco a poco el barrio Cieneguita en Limón. La Nación.

Cortés, J., Jiménez, C., Fonseca, A., \& Alvarado, J. J. (2010). Status and conservation of coral reefs in Costa Rica. Revista de Biología Tropical, 58 (suppl.1), 33-50.

Denyer, P., Arias, O., \& Personius., S. (1994). Efectos tectonicos del terremoto de Limon, Costa Rica. Rev. Geol. Amer. Central, Volumen especial, 39-52.

Denyer, P., Cárdenes, G. \& Kruse, S. (2004). Registro histórico y evolución de la barra arenosa de Puntarenas, Golfo de Nicoya, Costa Rica. Revista Geológica de América Central, 31, 45-59.

Dingler, J. R. (2005). Beache processes. En M. Schwartz, Encyplopedia of coastal science (pp. 161-169). Netherlands: Springer.

Finkl, C. J. (1993). Pre-emptive strategies for enhanced sand bypassing and beach replenishment activities in southeast Florida: a geological perspective. Journal of Coastal Research (18), 59-89.

Gracia, F. J., Anfuso, G., Benavente, J., Río, L. D., Domínguez, L., \& Martínez, J. A. (2005). Monitoring coastal erosion at different temporal scales on sandy beaches: application to the Spanish Gulf of Cadiz coast. Journal of Coastal Research, 22-27.

Gerrard, J. (2007). Fundamentals of Geomorphology (2a . ed.). New York: Routledge. 
Herrera, W. (1986). Clima de Costa Rica: Vegetacion y clima de costa Rica. San José: EUNED.

IMN. (2017). Clima de Costa Rica: el clima y las regiones climáticas de Costa Rica. Recuperado el 07 de Noviembre de 2017, de Instituto Meteorológico Nacional: https://www.imn.ac.cr

Lizano, O. (Enero de 2007). Climatología del viento y oleaje frente a las costas de Costa Rica, parte 1. Recuperadode MIOCIMAR: http:// miocimar.ucr.ac.cr/sites/default/files/articulos/CLIMATOLOGIA_ DEL_VIENTO_Y_OLEAJE_FRENTE_A_LAS_COST.pdf

Lizano, O. G. (2013). Erosión en las costas de Costa Rica, incluyendo la Isla del Coco. INTERSEDES, 14 (27), 6-27.

Lizano, O. G. \& Salas, D. M. (2002). Variaciones geomorfologicas en los ultimos 50 anos de la Isla de Damas, Quepos, Costa Rica. Revista de Biología Tropical, 49, 171-178

Marshall, J. S. (2007). Chapter 3 The Geomorphology and Physiographic Provinces of Central America. In G. (Bundschuh, J. \& Alvarado (Ed.), CENTRAL AMERICA: GEOLOGY, RESOURCES AND HAZARDS (pp. 1-51). Taylor \& Francis, London.

Masselink, G. (2012). Coasts. En J. Holden, An introduction to Physical Geography and the Environment ( $3^{\mathrm{a}}$ ed., p. 876). London: Pearson Education Limited.

Moore, L. J. (2000). Shoreline mapping techniques. Journal of Coastal Research, 16(1), 111-124.

Mora, C. (7 de Marzo de 2015). Cieneguita, barrio limonense, estrena nuevas canchas deportivas, parques y una ciclovía. crhoy.com.

Murrillo, L. M. (2001). Las mareas en Costa Rica. Inter Sedes, 2 (2-3), 93-108.

Norabuena, E., Dixon, T. H., Schwartz, S., DeShon, H., Newman, A., Protti, M., Sampson, D. (2004). Geodetic and seismic constraints on some seismogenic zone processes in Costa Rica. Journal of Geophysical Research, 109, B11403.

Ojeda, J. (2000). Métodos para el cálculo de la erosión costera: revisión, tendencias y propuesta. Boletín de la Asociaión de Geógrafos Españoles.(30), 103-118. 
Ortiz, E. (2012). Cambios geoformológicos en el litoral Caribe y Pacífico de Costa Rica. Caso del Complejo Déltico de Sierpe. Revista Forestal Mesoamericana Kurú, 5 (15), 45-54.

PNUD. (2013). Informe nacional sobre desarrollo humano 2013. San José: Programa de las Naciones Unidas para el Desarrollo.

Prieto, A. (2017). Metodología para el cálculo, explotación y difusión de líneas de costa y tasas de erosión a medio plazo (1956-2011) en Andalucía. Tesis doctoral (pág. 336). Universidad de Sevilla.

Protti, M., Güendel, F. \& Malavassi, E. (2001). Evaluación del potencial sísmico de la Península de Nicoya. Heredia, Costa Rica: Editorial Fundación UNA.

Quesada, S. \& Molina, L. (20 de Enero de 2016). Calentamiento global dispara erosión en playas de Limón. Semanario Universidad.

Silva, R., Martínez, L., Hesp, P., Catalan, P., Osorio, A., Martell, R. \& Govaere, G. (2014). Present and Future Challenges of Coastal Erosion in Latin America. Journal of Coastal Research, 1-16.

Soto, M. (5 de junio de 2014). Mar arrebató 20 metros al Parque Nacional Cahuita en últimos 15 años. La Nacion.

Taveira-Pinto, F., Silva, R., \& Pais-Barbosa, J. (2011). Coastal erosion along the Portuguese northwest coast due to changing sediment discharges from rivers and climate change. In Global change and baltic coastal zones (pp. 135-151). Springer, Dordrecht.

Thiele, E. R., \& Danforth, W. W. (1994). Historical shoreline mapping (I): improving techniques and reducing positioning errors. Journal of Coastal Research, 10(3), 549-563.

Vargas, G. (2006). Geografia de Costa Rica. San José: EUNED. 